\title{
La transformación de la topografía y del paisaje en la construcción del Monasterio de El Escorial
}

\section{The transformation of topography and landscape in the construction of the Monastery of El Escorial}

\author{
$\underline{\text { P. Chías Navarro }}^{(*)}$, T. Abad Balboa ${ }^{(*)}$
}

RESUMEN

Aunque el lugar elegido para construir el monasterio fue una explanada soleada y protegida en la ladera del monte Abantos, lo que en un principio pareció ser una topografía amable pronto se reveló como un factor importante a tener en cuenta en el diseño y el proceso de construcción de la fábrica. Las importantes dimensiones de ésta requirieron la construcción de una plataforma sobre la que asentar el edificio y sus jardines, a la vez que la proximidad de la montaña hizo necesario retirar las tierras inmediatas a las fachadas septentrional y occidental. En consecuencia fue necesario prever la construcción de potentes muros de contención, rellenar de tierra la plataforma, explanar, y retirar las tierras sobrantes a zonas próximas como Terreros. La reconstrucción de la topografía original y del paisaje circundante, y las alteraciones que sufrieron durante el siglo xvı, son el objeto de la presente investigación.

Palabras clave: Monasterio de El Escorial; paisaje; territorio; patrimonio; topografía; Felipe II.

\section{ABSTRACT}

The place chosen to build the Monastery was a quite sunny wind-protected esplanade on the hillside of Mount Abantos. What formerly seemed a gentle slope, soon turned out to be one of the essential factors to be considered both in the design and the construction processes. The large dimensions of the building and its gardens needed to be laid down on a wide platform. On the other hand, huge amounts of earth must be dug out due to the vicinity of the rough mountainside. As a consequence, big retaining walls were built, and the platform was filled in with earth, while the remainings were removed to the next area of Terreros. Therefore the main target of this research is the recreation of the original topography and landscape surrounding the Monastery of El Escorial, as well as their transformations.

Keywords: Monastery of El Escorial; Landscape; Territory; Cultural Heritage; Topography; King Philip II.

${ }^{(*)}$ Escuela de Arquitectura, Universidad de Alcalá.

Persona de contacto/Corresponding author: pilar.chias@uah.es (P. Chías Navarro)

Cómo citar este artículo/Citation: Chías Navarro, P., Abad Balboa, T. (2016). La transformación de la topografía y del paisaje en la construcción del Monasterio de El Escorial. Informes de la Construcción, 68(543): e159, doi: http://dx.doi.org/10.3989/ic.15.142.

Licencia / License: Salvo indicación contraria, todos los contenidos de la edición electrónica de Informes de la Construcción se distribuyen bajo una licencia de uso y distribución Creative Commons Attribution License (CC BY) Spain 3.o. 


\section{INTRODUCCIÓN, ANTECEDENTES Y OBJETIVOS}

Entre los numerosos estudios que se han realizado sobre el Monasterio de El Escorial son muy escasas las referencias al soporte territorial, y más concretamente al paisaje y a la topografía. Merecen citarse por su interés los trabajos monográficos de Vicuña (1) y Andrés (2), que se centran respectivamente en los aspectos geológicos y geomorfológicos de la zona; por su parte, Cervera Vera (3) analiza la concepción del paisaje en el entorno más inmediato al monasterio, introduciendo el ya clásico concepto de «naturaleza urbanizada», y Chías y Abad (4) tratan sobre el agua y los aprovechamientos hidráulicos al servicio de la fábrica. A otro grupo de autores que puede verse representado por Francisco de Inza (5) se deben las aportaciones muy personales de «un observador producto del siglo $\mathrm{xx}$ ».

Los estudios topográficos relacionados con el patrimonio son particularmente escasos porque no es frecuente que los edi- ficios históricos estén tan documentados desde su fundación como sucede con el Monasterio de El Escorial. Y hasta ahora no se ha realizado ninguna investigación sobre la topografía original del sitio, ni sobre las alteraciones que sufrió a medida que se fue cumpliendo el programa de construcciones, con los consiguientes cambios en el paisaje debidos a tan importante movimiento de tierras. Es este el objetivo de la presente investigación, que se circunscribe en lo temporal al reinado de Felipe II, aunque en un futuro se abordarán los realizados en los siglos posteriores, y en concreto desde la construcción de la población en el siglo xviII.

El ámbito espacial en el que se desarrolla la investigación se extiende en sentido este-oeste desde el puerto de Malagón hasta El Escorial de Abajo, y desde Abantos hasta el arroyo del Batán, en sentido norte-sur. Esta limitación se justifica por los propios objetivos del estudio, que aborda los cambios en la topografía y los movimientos de tierra debidos a la construcción del monasterio. Obviamente se han incluido zonas pertenecientes a los actuales municipios de San Lorenzo y de

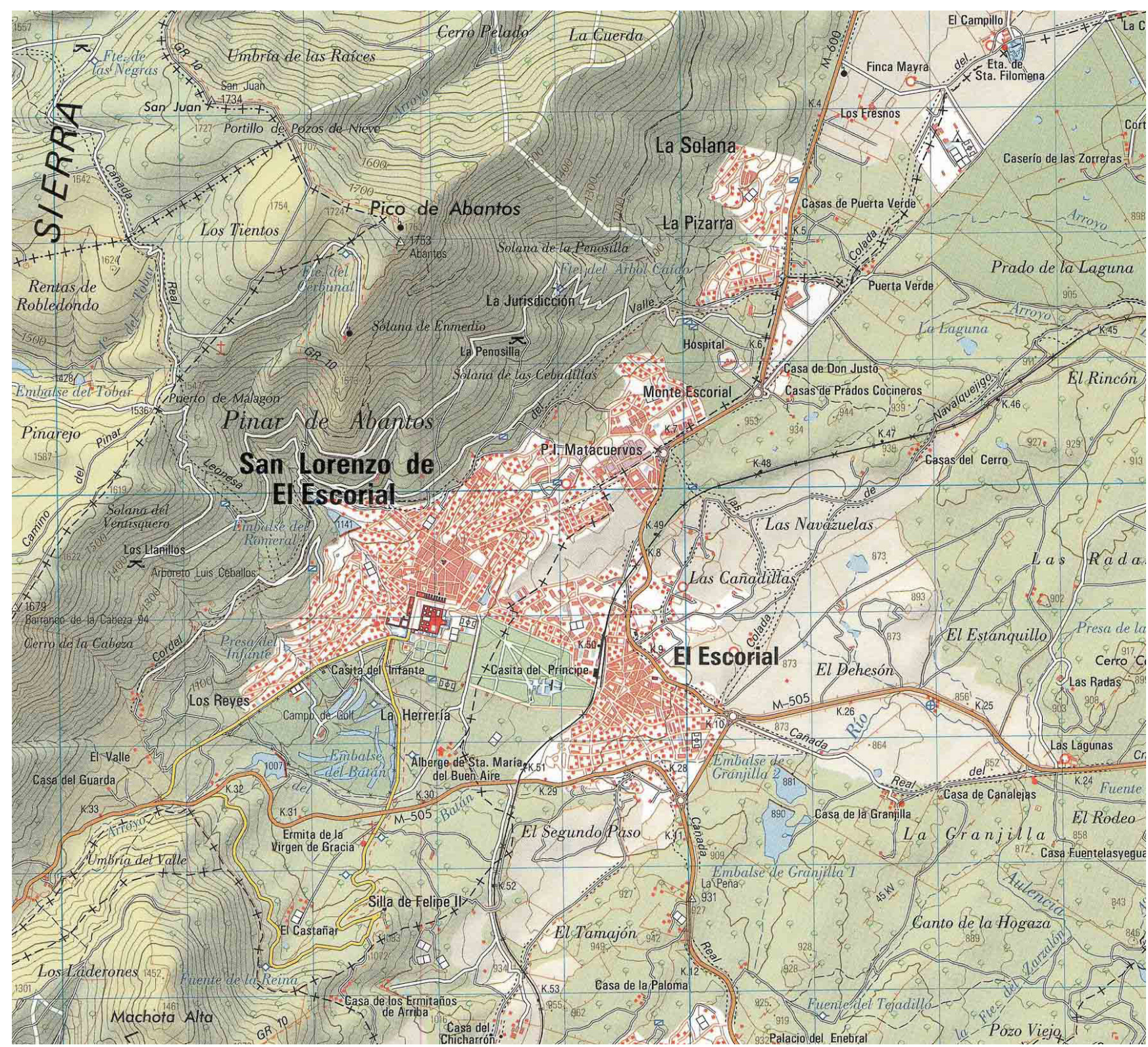

Figura 1. Ámbito espacial en el que se desarrolla la investigación. San Lorenzo de El Escorial, Mapa Topográfico Nacional hoja 533 (ed. 2002), E: 1/50.000. Detalle. 
El Escorial, puesto que carece de sentido considerar las artificiales divisiones administrativas establecidas desde 1792, y, por tanto, muy posteriores a la fundación.

\section{EL PROGRAMA Y EL LUGAR}

Cuando Felipe II volvió de Flandes en 1559 empezó a madurar la idea de construir un monasterio con un programa inicial de panteón, convento y palacio, contando para ello con la orden jerónima y con su arquitecto, Juan Bautista de Toledo.

Unas primeras trazas se presentaron al rey en enero de 1561 , probablemente resultado tanto de la experiencia funcional de los frailes en la construcción de otros conventos como del buen oficio del arquitecto, suscitándose entonces pocos puntos de desacuerdo entre las partes.

Simultáneamente se estaba buscando el emplazamiento ideal. Aunque no está del todo claro si las trazas precedieron a la elección del lugar, tanto el programa como las dimensiones aproximadas del cuadro ya estaban prácticamente decididas a principios de 1562 (6).

Fray José de Sigüenza (7) así lo manifiesta al decir que aquél se halló finalmente «en la ladera de esta sierra, junto a una pequeña población que se llama el Escorial, [...] se descubrió una llanura o plaza suficiente para una grande planta», cuyo esquema reprodujo en el manuscrito original, sin incorporarle ninguna referencia geográfica (8).

En una visita inmediatamente posterior que realizaron en abril el rey y Juan Bautista, éste «tenía hecha la planta de los principales miembros del edificio, aunque se fue siempre puliendo y mejorando, procurando se pusiesen lo más acomodado a los usos y menesteres, que es dificultoso acertar de la primera vez tantas cosas. Mandó Su Majestad que se acordelase el sitio, y se pusiesen las estacas por donde habían de abrirse los cimientos: y lo que hasta allí había sido majadas de pastores pobres, mudó el estado y el nombre, y se llamó sitio del Monasterio de S. Lorenzo el Real. / Quiso y parecióle así también al Arquitecto, que la casa no mirase tan puntualmente al mediodía que no tuviese un grado poco más de declinación al Oriente, porque el paño y perfil de Mediodía, donde había de ser la principal habitación de los religiosos y del aposento Real gozase más presto del Sol en el invierno, que era lo que más entonces se temía del sitio. Tiraron la línea de Levante a Poniente, que llaman los Cosmógrafos de longitud, por espacio de quinientos ochenta pies [...]. / De los extremos de esta línea de quinientos ochenta pies, sacaron otras dos perpendiculares de Norte a Sur, de setecientos y treinta y cinco pies, cerraron desde los dos extremos de estas dos líneas con la cuarta de otros quinientos y ochenta pies, y así quedó hecha una plaza cuadrangular que por la parte de Oriente y de poniente tenía ciento y cincuenta y cinco pies más que de Oriente a Poniente, y por aquí se fueron abrien- do los cimientos». Termina Sigüenza su descripción con una observación interesante sobre la topografía: «No estaba toda esta área llana, sino con altos y bajos, que aunque la vista no hacía mucho exceso, cuando echaron los niveles no fue pequeña la diferencia» (9).

\section{LA ALTIMETRÍA DEL SITIO}

Son muy numerosos y detallados los datos que sobre la construcción del monasterio aportan las fuentes escritas, incluyendo, como se verá, los relativos al movimiento de tierras. Sin embargo, la mayoría de las fuentes gráficas y cartográficas han proporcionado, salvo excepciones, informaciones más expresivas que precisas (10).

Para interpretar adecuadamente los datos gráficos se han adoptado dos datos de base: el primero es altimétrico y corresponde a la la altura de la Lonja medida por el Instituto Geográfico Nacional y establecida en 1.040 m sobre el nivel del mar, y el segundo se refiere a las unidades de medida empleadas en la obra, que concretamente establecen la unidad de longitud de un pie castellano, equivalente a unos $27,86 \mathrm{~cm}$.

Los datos de las fuentes se han completado con el imprescindible trabajo de campo, realizando mediciones in situ en las que se ha utilizado tanto cinta métrica como un distanciómetro láser y una estación total. Tomando como base la cota de la Lonja, los principales datos altimétricos obtenidos por medición directa o indirecta se resumen en la Tabla 1.

El dibujo más antiguo que aporta información fiable sobre la topografía del lugar durante la construcción del monasterio es el fechado hacia 1576 que se custodia en Hatfield House (Figura 2).

A pesar de tratarse de una perspectiva, hay tres puntos en la obra que evidencian lo ajustado del comentario de Sigüenza: la cimentación al descubierto del sector sureste del muro de los nichos, la cimentación de la Casa del rey, y el ángulo exterior de la Torre del Colegio.

Puesto que las dimensiones de estos tres elementos son conocidas, es posible deducir la importancia del terraplenado en todo el sector sureste y del relleno de la plataforma de los jardines, así como la pendiente de la ladera que amenazaba con su inmediatez a los muros del norte y el noroeste de la fábrica. Así, la cota del punto más bajo del terreno se sitúa en la base de la arista del ángulo sureste del muro de los nichos. Considerando que la altura de éste es de unos 19 pies castellanos (unos 5,30 m) entre el ándito hasta la plataforma del jardín, y que es visible la cimentación del muro en unos 18 pies, se estima que esta cota del terreno se encontraba a unos 27 pies por debajo de la plataforma del jardín, es decir, a una cota aproximada de $1.022 \mathrm{~m}$.

Tabla 1. Cotas altimétricas principales en monasterio y su entorno inmediato. En azul, las cotas superiores a la de la Lonja, tomada como referencia. En rojo las cotas inferiores.

\begin{tabular}{|l|c|c|c|c|c|}
\hline & $\begin{array}{c}\text { Cota de la Lonja } \\
\text { (datos IGN) }\end{array}$ & $\begin{array}{c}\text { Cota de la calle de } \\
\text { los Doctores* }\end{array}$ & $\begin{array}{c}\text { Cota del “andar de } \\
\text { la casa" }\end{array}$ & $\begin{array}{c}\text { Cota del Jardín de } \\
\text { los Frailes }\end{array}$ & $\begin{array}{c}\text { Cota del ándito de la } \\
\text { huerta }\end{array}$ \\
\hline Metros & $1.040,00$ & $\begin{array}{c}1.046,12 \\
(+6,12)\end{array}$ & $\begin{array}{c}1.041,40 \\
(+1,40)\end{array}$ & $\begin{array}{c}1.036,23 \\
(-3,76)\end{array}$ & $\begin{array}{c}1.030,95 \\
(-9,05)\end{array}$ \\
\hline Pies & 0,00 & +22 & +5 & $-13^{1 / 2}$ & $-32^{1 / 2}$ \\
\hline
\end{tabular}

* Medida en el mismo plano de sección que la de Herrera. 

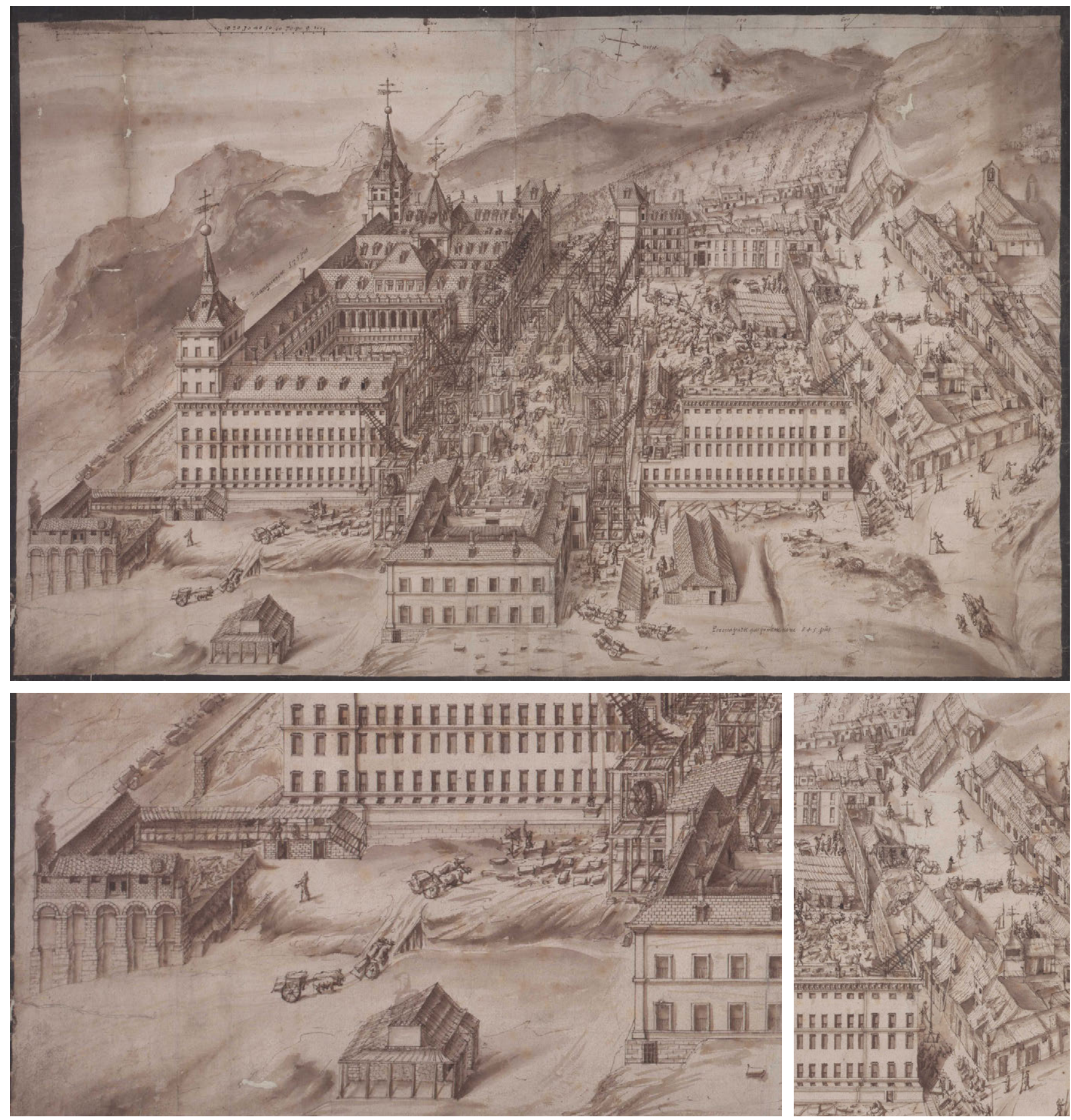

Figura 2. Perspectiva aérea de la construcción de la fábrica del monasterio atribuida a Fabricio Castelo, ca. 1576. Detalle de los ángulos sureste y noroeste. Colección de Lord Salisbury, Hatfield House, Hertfordshire, Reino Unido.

El segundo dibujo que aporta datos sobre los desniveles en el entorno de la fábrica se debe a Juan de Herrera: está fechado en 1587 y se trata del alzado lateral de levante de la Primera Casa de Oficios (Figura 3).

El alzado incluye una sección acotada de la crujía septentrional del monasterio, de la Lonja y de la calle de los Doctores (hoy Floridablanca). La lectura detallada de las cotas no sólo aporta una idea de la importancia que Herrera daba a las proporciones (11), sino que permite comprobar que el desnivel entre la Lonja y la calle era en este punto de 22 pies (unos 6,10 m).

Por otra parte, la calle asciende hacia poniente con una pendiente del $2 \%$ hasta la fachada oeste de la Casa del Ministerio de Estado (distante $230 \mathrm{~m}$ ), donde el desnivel supera los $10 \mathrm{~m}$. A partir de este punto la pendiente aumenta considerablemente (ver el plano topográfico de la Figura 7).

El tercer documento de la época es el cuarto diseño de Juan de Herrera y Pedro Perret, grabado en el mismo año de 1587. Se trata de una sección transversal del edificio por un plano aproximadamente norte-sur con la pequeña desviación en la orientación respecto al norte que se impuso a toda la fábrica para mejorar el soleamiento. Esta ligera desviación de «un grado» hacia el suroeste (en realidad es de $12^{\circ}$ respecto al norte geográfico) ya fue advertida por Sigüenza (9) cuando se efectuó el replanteo. En el ángulo inferior derecho se representa una sección de los descendederos a la huerta desde el 
jardín de los frailes, que permite relacionar la cota del ándito (la más baja), con las del «andar de la casa» y de la Lonja (véase la Tabla 1), y comprobar las cotas mostradas en las imágenes proyectadas con las reales (Figura 4).

Pero si los dibujos de Herrera grabados por Perret introducen algunas licencias gráficas y dimensionales debido a su carácter eminentemente propagandístico, no sucede lo mismo con el levantamiento realizado por los ingenieros Balthazar Bécaud y Bernardo Fillera en 1759, por encargo del conde de Aranda a la Academia de Bellas Artes de
San Fernando (12). El alzado de la fachada principal o de poniente (inédito hasta entonces, ya que sólo se conocía a través de dibujos en perspectiva) revela con detalle el desnivel existente entre la Lonja y el camino de Robledo de Chavela bajo los arcos del paso entre la Botica y la Compaña (Figura 5).

Siguiendo la línea de sección ABC que debía figurar en la planta (hoy perdida), el dibujo muestra la Lonja seccionada y el alzado oeste de la Botica, y permite comprobar el importante desnivel existente entre el ramal norte del camino peri-

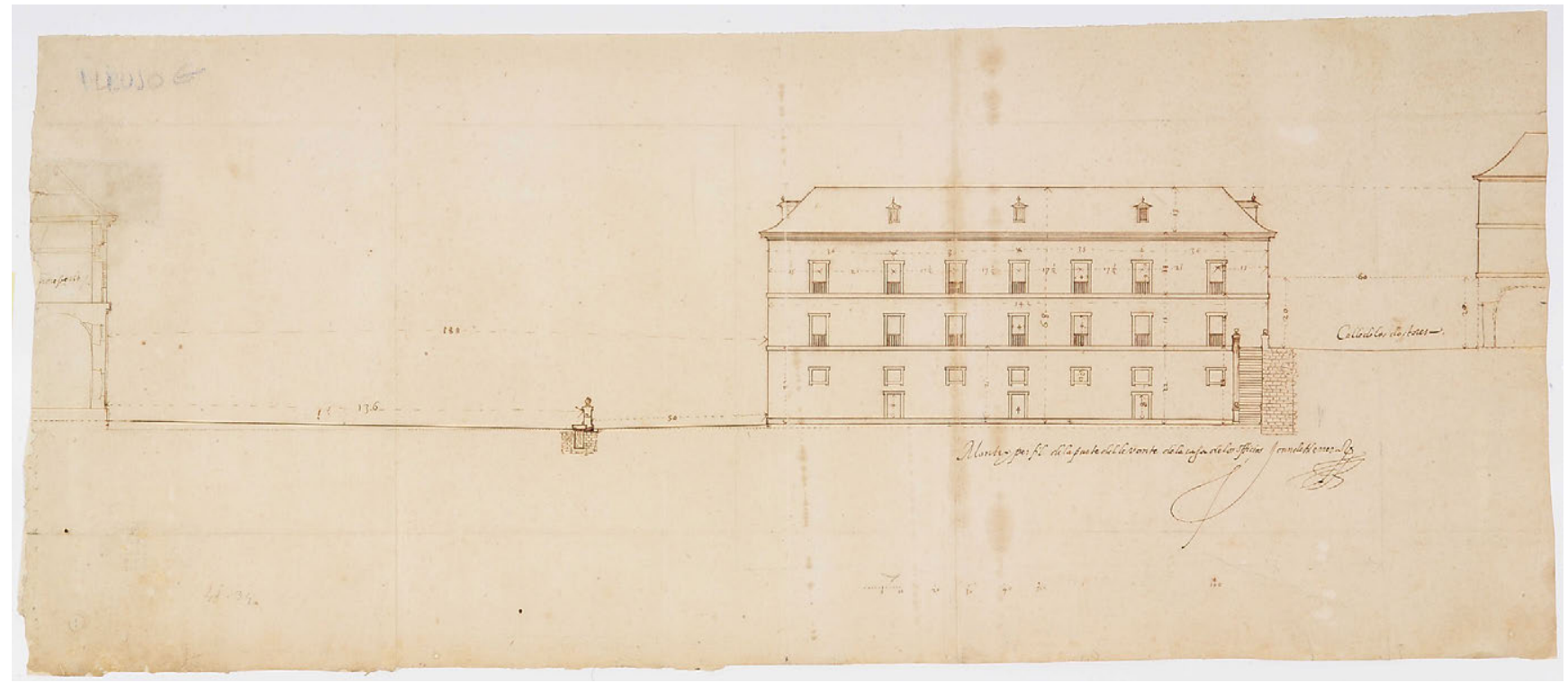

Figura 3. Juan de Herrera, 1587. Alzado lateral de levante de la Primera Casa de Oficios. Real Biblioteca, Patrimonio Nacional, Madrid, Signatura IX/M/241/1(44).

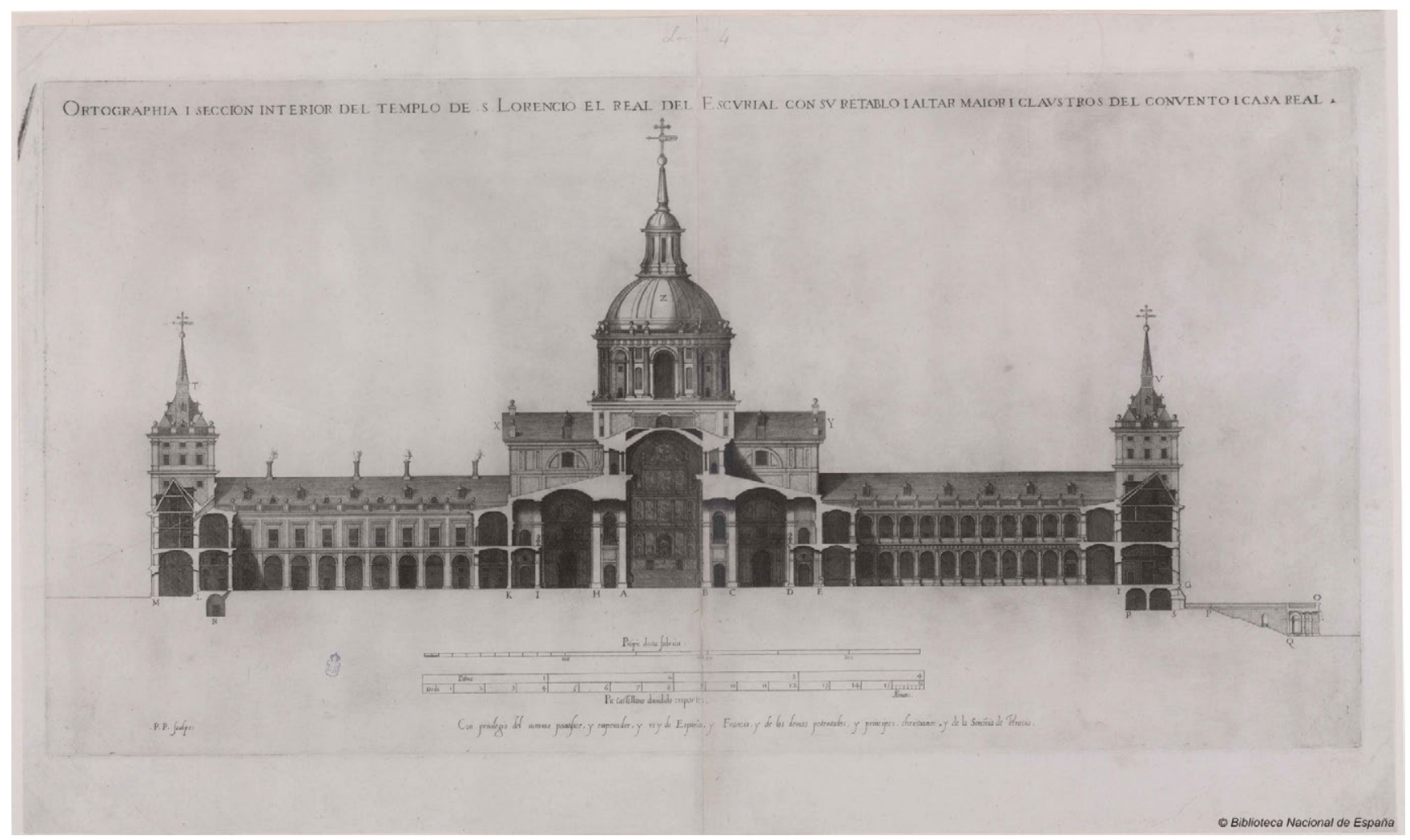

Figura 4. Juan de Herrera y Pedro Perret, 1587. Ortographia i Seccion Interior del Templo de S. Lorenzo el Real del Escurial con su Retablo i Altar Maior i Claustros del Convento i Casa Real (Cuarto Diseño). Biblioteca Nacional de España, Madrid, Signatura INVENT/28844. 


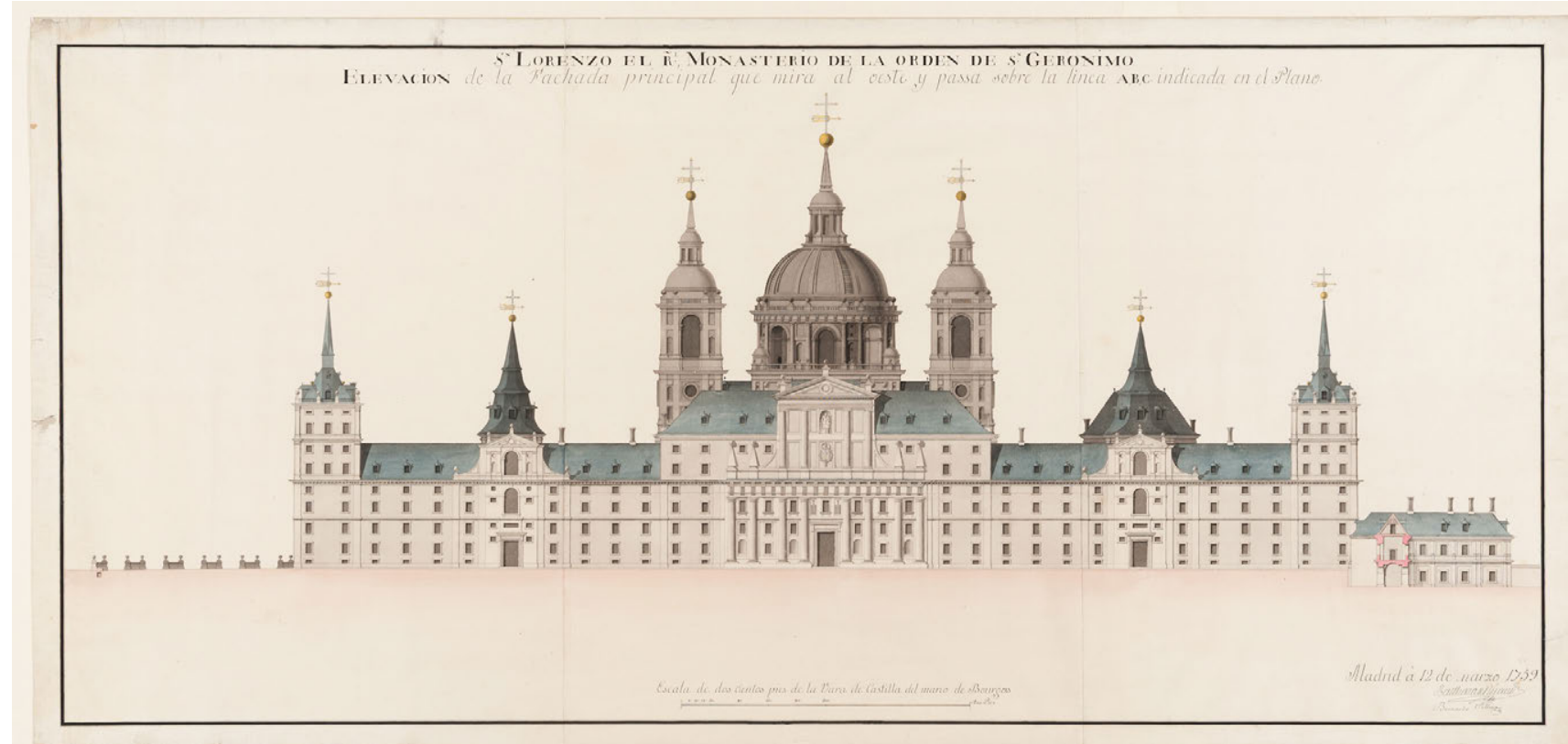

Figura 5. Balthazar Bécaud y Bernardo Fillera, 1759. Elevación de la Fachada principal que mira al oeste y passa sobre la línea A,B,C indicada en el Plano. Collection Centre Canadien d'Architecture, Montréal, DR1986:0722.

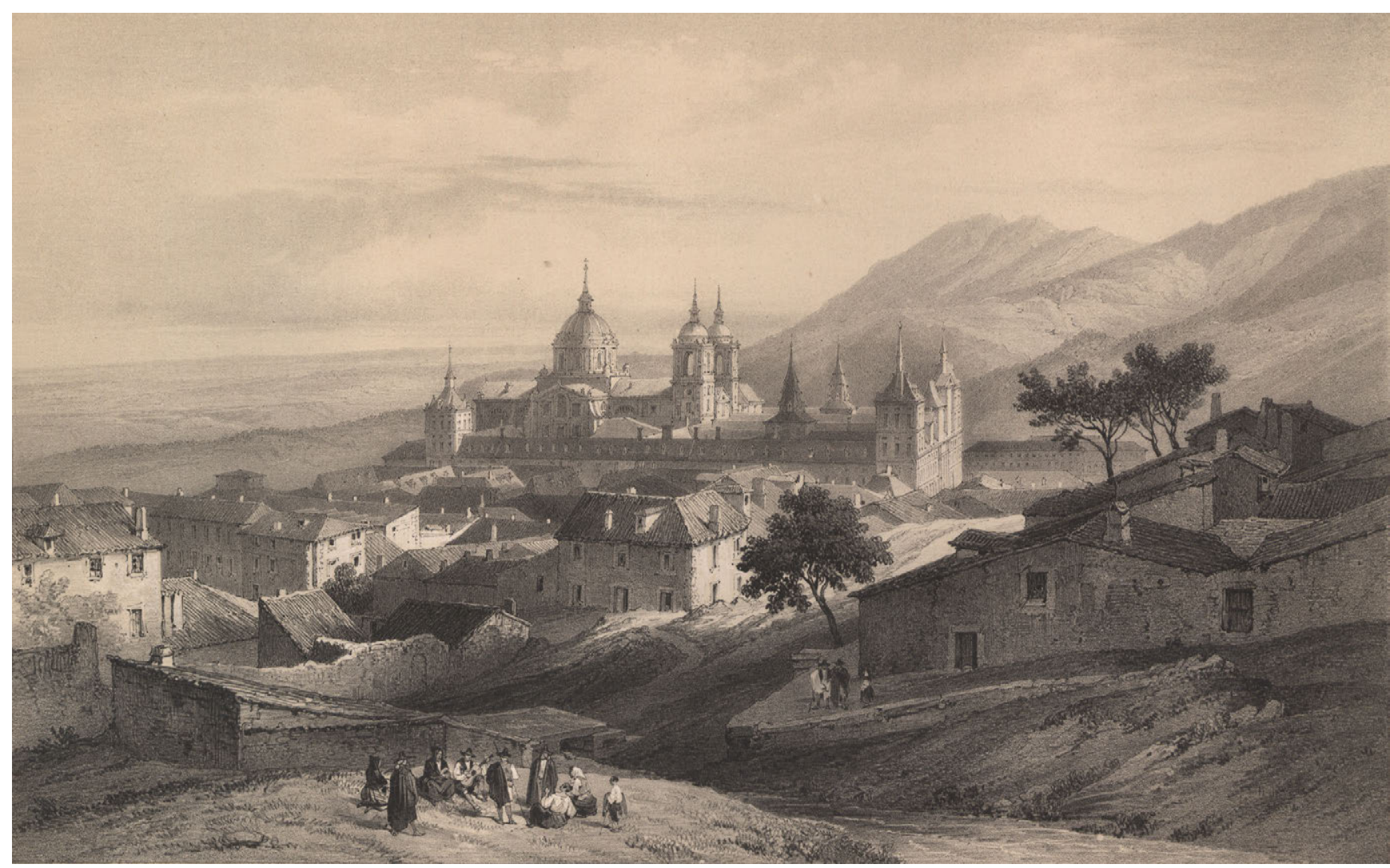

Figura 6. Nicolas-Marie-Joseph Chapuy, 1844-1851. Le Moyen-Âge Monumental et Archéologique. Vues et détails des monuments les plus remarquables de l'Europe, depuis le VI jusqu'au XVIII ${ }^{e}$ siécle. Lithographiés par les principaux artistes d'aprés les dessins de Chapuy. Paris, Lévy fils editeur. Vol. 3. Real Biblioteca, Patrimonio Nacional, Madrid, Signatura IX/M/106 (66).

metral y la citada arquería (260 m de desarrollo longitudinal con una pendiente del $1,54 \%)$.

Otro grupo de fuentes gráficas que aportan información sobre el paisaje del entorno del monasterio son las que podrían calificarse de expresivas. Muy numerosas desde el siglo XVII, entre ellas merecen citarse los cuadros de Mi-
chel-Ange Houasse, de principios del siglo xviII (13), o las litografías de Chapuy realizadas casi siglo y medio después (Figura 6), donde se aprecia claramente la abrupta topografía del Sitio.

Por otra parte, si consideramos los planos generales de San Lorenzo realizados en el siglo xviII, el dibujado por Gianbat- 
tista Novello en torno a 1740 carece de cualquier representación topográfica, que sólo se adivina por la presencia de algunos muros de contención. Asimismo el Plan topográfico de todo el Sitio y geométricos de las casas propias de S. M. realizado por M. Merlo en 1785, aún utiliza los códigos antiguos de representación de la topografía por sombreado, intuitivos pero carentes de precisión.

Hay que esperar a la segunda mitad del siglo xix para contar con un levantamiento planimétrico y altimétrico de precisión, llevado a cabo con fines catastrales por la Junta Ge- neral de Estadística entre 1861 y 1870, siendo director de la misma el eminente cartógrafo Francisco Coello (14). Este proyecto de Topografía Catastral de España se dibujó en hojas a las escalas 1:2.00o (rústica) y 1:500 (urbana), con curvas de nivel cada $5 \mathrm{~m}$. Las minutas de las primeras se pasaron a limpio generando hojas de $1 \mathrm{~km} \times 1 \mathrm{~km}$, razón por la que se denominaron «kilométricas». Las hojas correspondientes a los municipios de San Lorenzo y de El Escorial nos han servido de base para realizar el plano de la topografía original y modificada del Sitio (Figura 7), así como los perfiles (Figura 8).

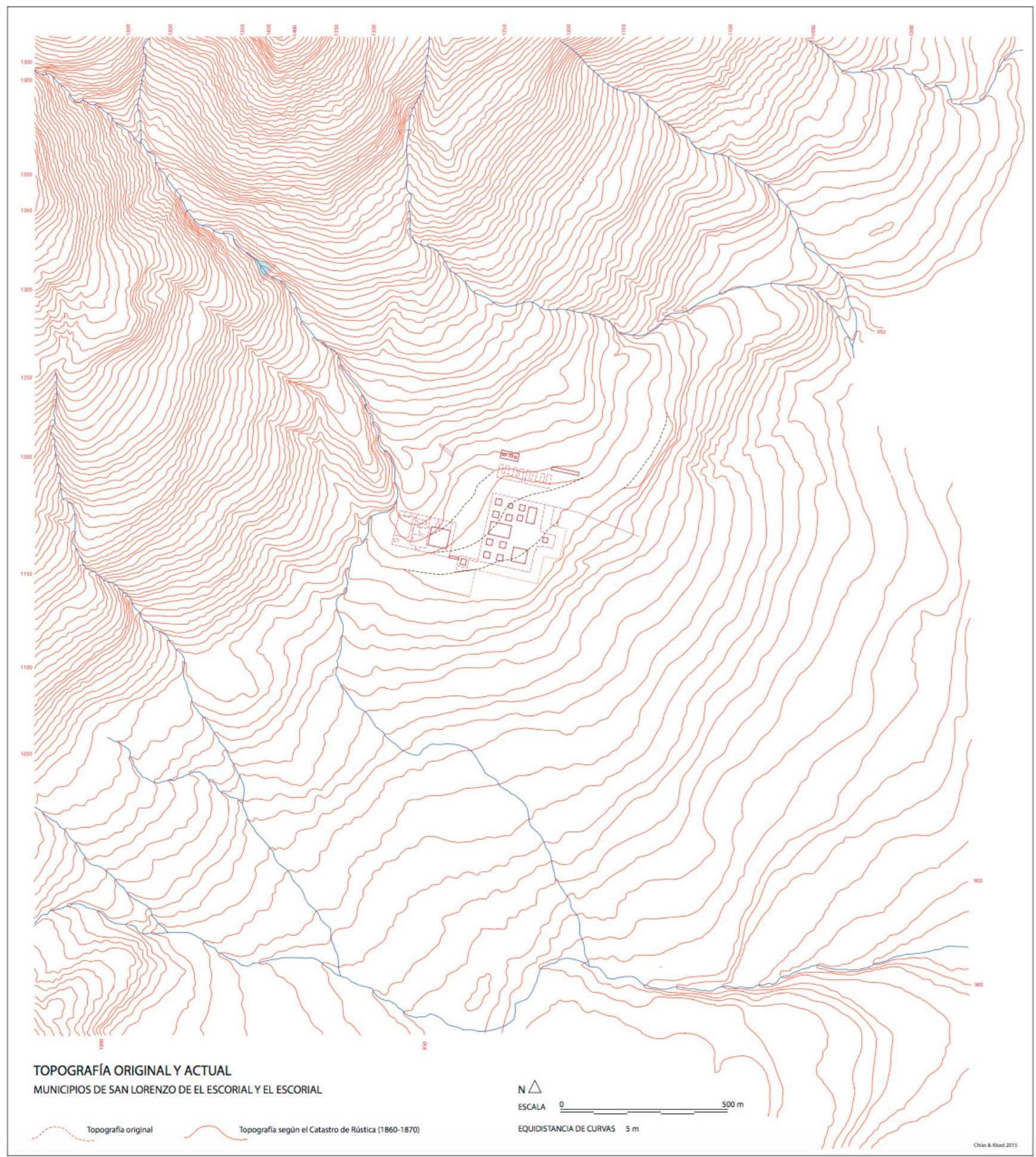

Figura 7. Pilar Chías y Tomás Abad, 2015. Topografía original y modificada del Sitio en el siglo xvi. Plano elaborado con datos de las Hojas kilométricas, municipios de San Lorenzo y de El Escorial. Escala 1:2000. Curvas de nivel cada $5 \mathrm{~m}$. 


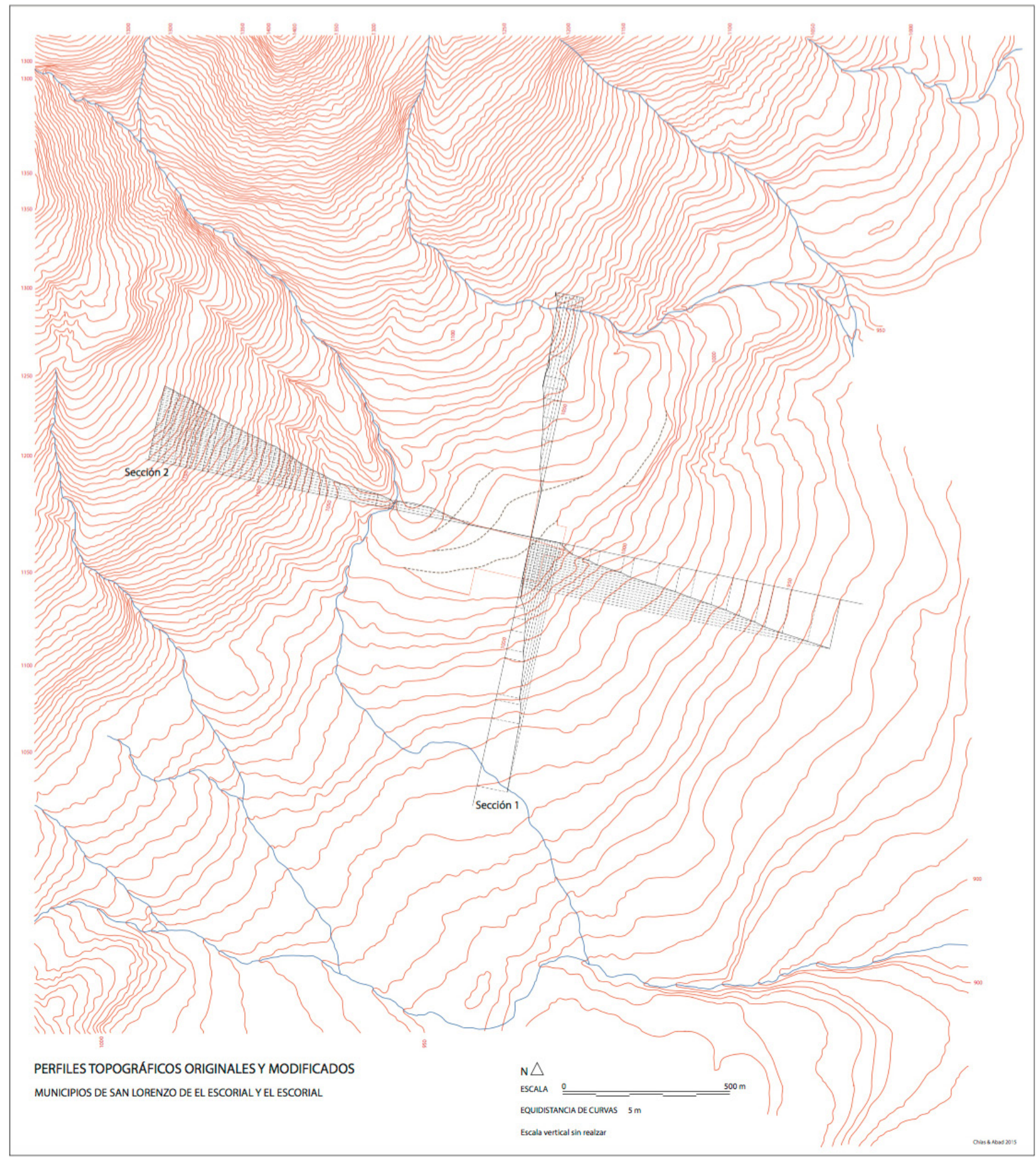

Figura 8. Pilar Chías y Tomás Abad, 2015. Perfiles topográficos originales y modificados. La sección topográfica 1 se ha realizado por el mismo plano que el dibujo de Juan de Herrera de 1587.

Finalmente, entre los mapas y planos elaborados con precisión hay que mencionar la serie del Mapa Topográfico Nacional a escala 1:50.00o, redactada por el Instituto Geográfico Nacional, que fue heredera directa de los trabajos de la Junta General de Estadística. La primera hoja de San Lorenzo (n. ${ }^{\circ} 533$ ) se publicó en fecha tan temprana como 1877 .

Otro plano posterior que incluyó datos fiables sobre la topografía del Real Sitio es el publicado en 1926 por Otto
Jürgens (15), dibujado a escala 1:10.00o con curvas de nivel cada $5 \mathrm{~m}$, formado con datos tomados de las Hojas kilométricas.

\section{DECISIONES EN TORNO AL MOVIMIENTO Y CONTENCIÓN DE TIERRAS}

Desde el primer momento se tomó conciencia de la importancia que tenía el movimiento de tierras en la obra y la construcción de muros de contención. 
La actividad en este caso se concentró en los siguientes puntos: en el muro de los nichos, cuya función sería la de crear la plataforma horizontal de los jardines pensiles del monasterio; en su prolongación por el norte y por el oeste, para contener respectivamente las tierras de la Plaza de la Parada y camino de los Álamos por el norte, y del camino a Robledo de Chavela por el oeste, y en la explanación de la Lonja, despejando la pendiente de Abantos para construir la calle perimetral.

El muro de los nichos se concibió para soportar la plataforma artificial de los jardines. Varios documentos fechados en julio de 1564 tratan sobre ellos, decidiéndose que «las paredes de los nichos del terraplén tienen los gruesos necesarios para sustentar el dicho terraplén, considerando que ha de tener veinticinco pies de alto y en el largo que tiene, decimos que nos parece que tiene suficientes gruesos y que va bien fabricado, y en lo que queda debajo de tierra decimos que se puede excusar labrarlo curiosamente más de sus esquinas y lo de entre medias de tosco yendo bien ligado con sus cruceros y ligadores» (16) (véase la Figura 2).

También por entonces firmó el aparejador de cantería de la obra Pedro de Tolosa un tanteo de presupuesto: «La memoria de lo que valen los nichos y entrenichos almohadillados en todo el lienzo o fachada hacia la dehesa y la parte de Oriente que es a la parte de El Escorial, hasta dar o topar con la Iglesia y las escaleras que están ordenadas en los dichos nichos en las torres para subir de lo bajo a lo alto del jardín, que es a nivel de las cantinas en cada torre, dos escaleras excepto en la torre de la enfermería que ha de haber una con sus paredes, y pilares y cubiertas y 'capiletas' de las entradas sendas escaleras, como las zanjas destas escaleras y paredes sobre que cargan las escaleras con las fuerzas de los lados como los nichos del que vienen y están ordenados a hacer. / [Al margen:] Ha de haber dos. / De otro de los nichos hasta en lo alto de diecinueve pies y medio, con los cuales subimos o acabamos de subir desde el plinto que se ha de asentar para comenzar a asentar las almohadas y plantar los árboles hasta lo alto del nivel de las cantinas sin tocar al muro principal de los nichos, digo sólo contando el haz de las almohadas valen XXIII mil DCCC XXXII [23832] ducados y medio, juntamente con todo lo sobredicho dentro de los XIX pies y medio la suma arriba dicha.» A lo que el rey apostilló al margen, según su costumbre: «Saber la diferencia haciéndose otra escalera más de las que están ordenadas por Juan Bautista, como antes eran siete han de ser ocho.» Y continúa Tolosa: «Las escaleras que vienen en las torres costarán antes CC. ducados más que menos por estar en ladera más baja, costarán todas las ocho escaleras trece mil CC. [13200] ducados [...] / La delantera de los nichos, digo los nichos y entrenichos y el lienzo de la parte de la dehesa y la parte que va a dar a la Casa de Su majestad, costarán haciendo aceras II. U. CC. [2200] ducados. / Digo sólo las aceras» (17).

Desde el principio el diseño del muro de los nichos y el de los descendederos fue controvertido, así como el gasto que requerían, y así lo manifiesta en una carta el prior fray Juan de Huete dirigida al rey a través de su secretario Pedro del Hoyo: «La pared de los nichos se baja buscando según al orden que Juan Bautista dejó a su aparejador, que es que los huecos de los nichos van ya formados en lo que ha de aparecer fuera de tierra sino lo que ha de quedar debajo de ella porque es necesario quedar hondo donde se han de plantar los naranjos, mas no subirán más de hasta donde se ha de hacer la elección de los nichos que han de parecer que según tenemos enten- dido irán bien costosos según el diseño que de ellos hemos visto, y si no pensaremos que Su Majestad lo quiere así para su contentamiento, ya le habríamos suplicado fuese servido que aquel gasto se moderase, pues harán tan buen servicio yendo llanos dándoseles buena gracia como de la manera que los mandan hacer, y lo mismo siento de unos escalerones que van imaginados para bajar del jardín a las huertas bajas porque no podrán dejar de afear el jardín, pues cada escalera le ha de atravesar y cortar e impedir el paseo largo del jardín y el gozarlo todo sin estropiezo, que cierto con estos aderentes yo creo se gastarán más en los nichos de cincuenta o sesenta mil ducados que no es poco dinero donde hay tantos gastos y a los oficiales dáseles poco de gastar dineros ajenos y alargar la cura.»

No era una parte exenta de dificultad, pues aunque en agosto «va hecha harta obra en solo el lienzo del mediodía, aunque no llegamos con mucho al estado donde se han de erigir en lo que ha de parecer, porque por algunas partes van hondos los fundamentos y los muros son muy gruesos y consumen mucha materia y tiempo» (18).

La buena marcha de este muro permitió que entre agosto y octubre del mismo año el rey pudiera disponer que en el ángulo suroeste de la fábrica se hiciera un muro de contención que, partiendo de la Torre de la Botica, se prolongase hacia poniente. Este muro y sus potentes contrafuertes fueron embebidos posteriormente en los muros del sótano de la Galería de Convalecientes, pero en origen se plantearon para conformar el cierre meridional de la explanación de la plaza o Lonja occidental, y las tierras extraídas servirían para nivelarla (19). Sin embargo, y en parte debido a la organización de la obra y el acarreo de materiales, los trabajos en los nichos se prolongarían por fases en la zona de poniente hasta mediados de 1577, y en la de levante hasta 1583. El último tramo fue el de la zona de la Botica y el cierre del Estanque, para el que se dieron las condiciones en mayo de 1585 .

Casi al final de la obra se acometió también el acondicionamiento y la nivelación del entorno del edificio. Así, en este mismo año de 1585 «Miguel García de Susaña se obliga a ahondar, cavar y sacar todos los estadales de tierra de la delantera del pórtico principal por la parte de poniente y cierzo» (20). Pero en esta fase ya no era preciso rellenar la plataforma del jardín, por lo que se buscó otra zona a la que trasladar la tierra sobrante. Ésta se halló al norte del monasterio en el camino de Guadarrama, en un lugar que desde entonces se denominó Terreros, como consta en un documento de julio de 1586 en el que se concierta «con Alonso Álvarez para cavar y sacar la tierra frontera de la plaza que arrima con el terrero, de largo hasta las estacas de los 250 pies en la fachada del norte y lo ahondará en un pie más bajo de la dicha fachada y llevará la tierra al Terrero» (Figura 9).

Tres años después, en abril de 1589, al desmantelarse parte de los talleres que habían servido a la construcción del monasterio y que se situaban en la Lonja norte, junto a las fachadas del colegio y del palacio, se concertaría «con Pedro Ramos para cavar y sacar toda la tierra y piedra que hay en la calle que sube desde el taller de Antonio de Recas, carpintero, hasta la esquina de la fragua de Su Majestad, todo lo que cae entre el pretil de la plaza del pórtico hasta las casas y talleres que hay en la dicha calle arrimadas al plantel, dejando ocho pies de paso delante de las dichas casas, porque de presente no se han de derribar y además sacará toda la tierra en la 


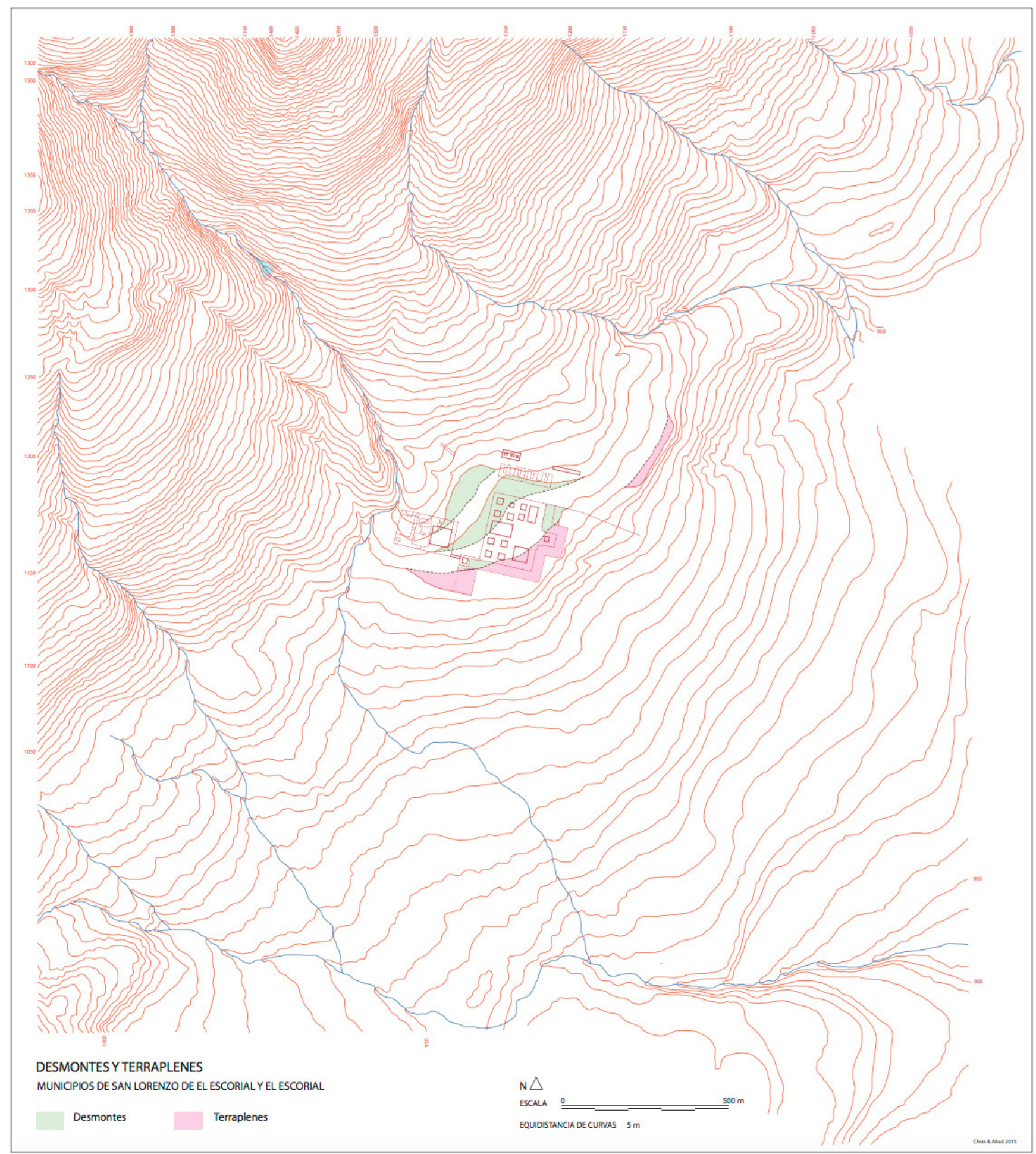

Figura 9. Pilar Chías y Tomás Abad, 2015. Plano de los desmontes y terraplenes realizados con motivo de la construcción del monasterio y sus dependencias en el siglo XvI.

plaza más arriba donde está el taller de la madera, volviendo al levante hacia las casas de los oficios hasta llegar derecho a la torre del colegio"; también «con Juan del Real para cavar, sacar y llevar la tierra a los terreros, que se les ordenare, desde la plaza de la lonja norte», y con «Juan García de Fraguas [que] se obliga a transportar la tierra a los terrenos que se saca de la parte de la lonja que mira a la casa de los oficios de Su Majestad» (21).

Esta explanación de Terreros sirvió para ubicar posteriormente la Ballestería y varios cuarteles. Quedaron muy daña- dos tras la Guerra de la Independencia, pero la plataforma aún es perfectamente reconocible a oriente de la carretera de Guadarrama (Figura 10).

\section{CONCLUSIONES}

El lugar elegido para levantar el monasterio resultó más accidentado de lo que se previó en un principio.

En sentido norte-sur el desnivel entre la calle de los Doctores y el ándito de la huerta alcanza los 15,47 m, aumentando 


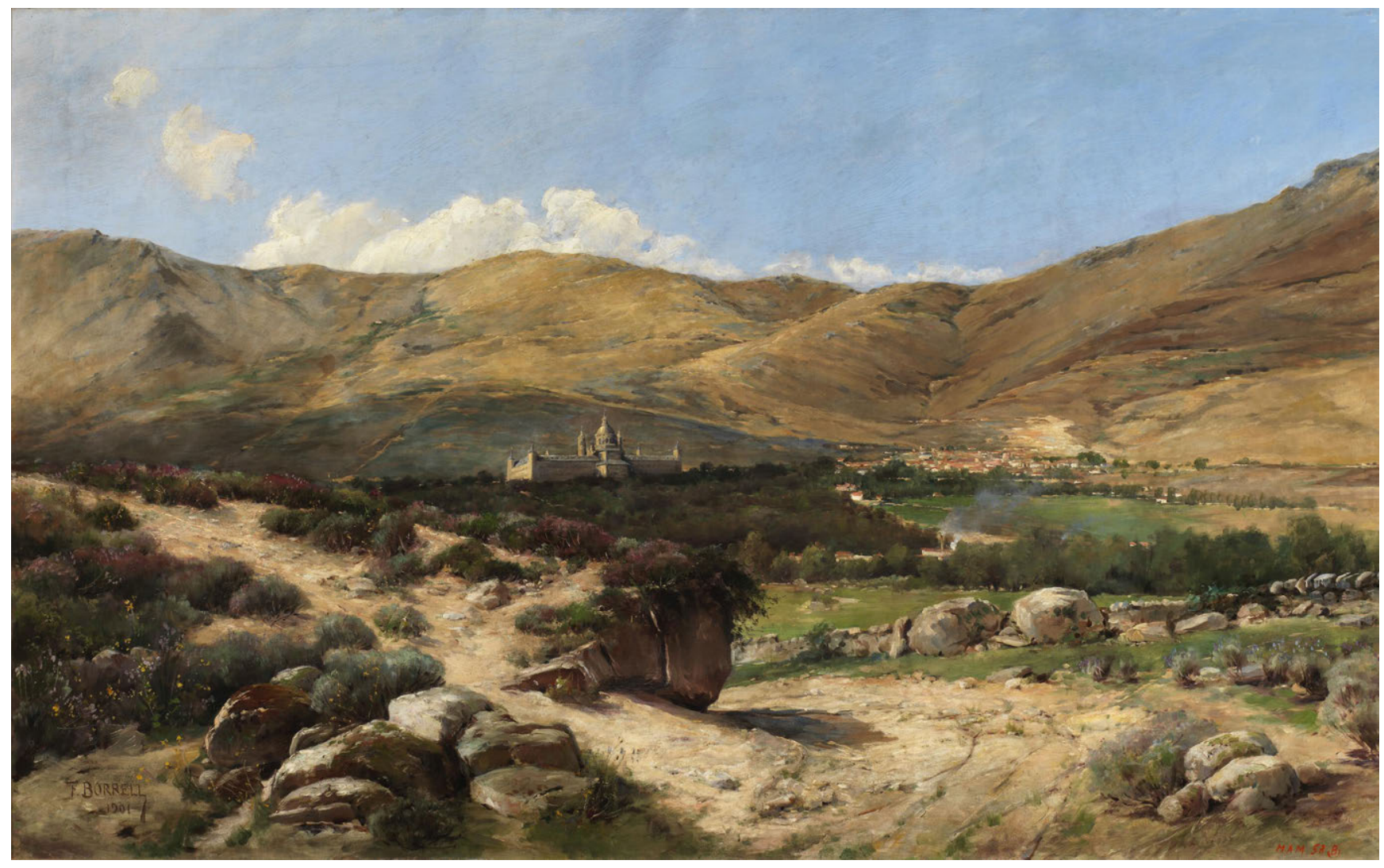

Figura 10. Félix Borrell, 1901. Paisaje de El Escorial. Congreso de los Diputados, Madrid (Depósito del Museo del Prado).

bruscamente tanto hacia la ladera de Abantos por el norte como hacia el arroyo del Batán por el sur. Lo mismo sucede entre El Plantel, situado frente a la fachada principal del monasterio, y el Bosquecillo, al este, descendiendo gradualmente hasta los 940 m de altitud de El Escorial de Abajo. La calle de los Álamos que desde el siglo xvi enlaza ambas poblaciones, aún mantiene una pendiente del 7,7 \% en una distancia de unos $1.300 \mathrm{~m}$.

Fue necesario acometer una serie de obras importantes para contener las tierras, construir plataformas, desmontar para dar cabida a nuevas construcciones y nivelar. La topografía y su tratamiento se convirtió en una parte importante del proyecto, y también en un condicionante esencial durante todo el proceso de construcción.

Más tarde tan accidentada topografía supuso un problema muy importante para el crecimiento urbano a partir del siglo xviII, requiriendo de nuevo la construcción de numerosos muros de contención y de escaleras, y dificultando en definitiva el desarrollo de un trazado barroco a semejanza de otros Reales Sitios.

\section{REFERENCIAS}

(1) Vicuña, C. (1929). Los minerales de El Escorial, con una descripción geológica del circo del mismo nombre. San Lorenzo de El Escorial: Imprenta del Real Monasterio de El Escorial.

(2) Andrés, G. de (1975). Toponimia e historia de la Montaña Escurialense. Anales del Instituto de Estudios Madrileños, 11: $15-26$.

(3) Cervera Vera, L. (1986). El conjunto escurialense con naturaleza urbanizada. En El Escorial. La arquitectura del Monasterio (pp. 89-113). Madrid: Colegio Oficial de Arquitectos.

(4) Chías, P., Abad, T. (2014). La construcción del entorno del Monasterio de San Lorenzo de El Escorial. Agua, territorio y paisaje. Informes de la Construcción, 66(536): e046, doi: http://dx.doi.org/10.3989/ic.14.027.

(5) Inza, F. de (1963). El Escorial, su tiempo y el nuestro. Arquitectura, 56: 41-50.

(6) Instituto de Valencia de Don Juan, Madrid, Envío 61, I, fols. 8-19 (28 de febrero de 1562).

(7) Sigüenza, J. de (1605). Tercera parte de la Historia de la Orden de San Gerónimo Doctor de la Iglesia. Dirigida al Rey nuestro Señor Don Philippe III. Libro Tercero, Discurso II, pp. 535-541. Madrid, en la Imprenta Real. Biblioteca Nacional de España, Madrid, Signatura AHMo/172252.

(8) Sigüenza, op. cit. Mss. en la Biblioteca del Monasterio de El Escorial, Madrid, Signatura Ms. \&-II-22.

(9) Sigüenza, op cit. Discurso III, pp. 542-543.

(10) Chías, P. (2016). La iconografía del Monasterio de El Escorial: Tradición e innovación en cuatro siglos de imágenes impresas (I). Revista EGA (en edición).

(11) Wilkinson Zerner, C. (1996). Juan de Herrera. Arquitecto de Felipe II. Madrid: Akal, p. 45. 
(12) Marías, F. (2001). El Escorial entre dos Academias: Juicios y dibujos. Reales Sitios, 38(149): 2-19.

(13) Chías, P. (2013). Territorio y paisaje en el entorno del Monasterio de San Lorenzo de El Escorial: planos y vistas desde el dibujo de Hatfield House a Guesdon. Revista EGA, 22: 38-49, doi: http://dx.doi.org/10.4995/ega.2013.1687.

(14) Arístegui, A., Dávila, F., Ruiz, A.C., Sánchez, J. (2014). El Archivo Topográfico del IGN: Origen de la cartografía actual de España. Revista Catalana de Geografía, 19(50): http://www.rcg.cat/articles.php?id=314.

(15) Jürgens, O. (1992). Ciudades españolas. Su desarrollo y configuración urbanística. Madrid: Ministerio para las Administraciones Públicas, p. 349.

(16) Archivo General de Simancas, Obras y Bosques, Leg. 6. Carpeta «Parecer que algunos maestros dieron sobre lo de la obra del Monasterio», firmada por Rodrigo Gil y por el licenciado Gutierrez (5 julio 1564).

(17) Archivo General de Simancas, Obras y Bosques, Leg. 6 (julio 1564).

(18) Archivo General de Simancas, Obras y Bosques, Escorial, leg. 2, fol. 95 (6 julio 1564) y 108 (10 agosto).

(19) Chías, P. (2015). La Botica del Monasterio de San Lorenzo el Real de El Escorial: una visión desde la Arquitectura. En Gomis, A., Rodríguez Nozal, R. (eds.) De la Botica de El Escorial a la Industria farmacéutica: en torno al medicamento (pp. 23-66). Alcalá de Henares: Servicio de Publicaciones de la Universidad de Alcalá.

(20) Archivo del Monasterio de San Lorenzo de El Escorial, X-2.

(21) Archivo del Monasterio de San Lorenzo de El Escorial, X-8, XI-29 y XI-36. 